\title{
PARTICULARIDADES DE LA CONSTRUCCIÓN
}

\author{
Javier Prieto Veiga y Agustín Vallecillo Rodríguez, Ingenieros de Caminos*
}

\section{FASES DE CONSTRUCCIÓN}

Con la tecnología adoptada para este depósito, el proceso constructivo sigue las siguientes fases, de las que se van a comentar seguidamente sus aspectos característicos:

- Instalaciones de obra.

- Cimentación.

- Depósito exterior: Levantamiento del muro de hormigón armado y postesado.

- Cúpula metálica y Techo suspendido: Montaje en el fondo del Tanque interior (simultáneamente con la fase anterior).

- Cúpula metálica y Techo suspendido: Elevación con aire y fijación.

- Depósito interior: Montaje y soldadura de las virolas de la pared vertical.

- Depósito exterior: Montaje y soldadura de las chapas del "liner" (simultáneamente con la fase anterior).

- Depósito exterior: Hormigonado de la cúpula.

- Aislamiento del fondo del depósito interior.

- Depósito interior: Montaje y soldadura de las chapas del fondo.

- Depósito interior: Montaje de accesorios.

- Pruebas hidráulica y neumática.

- Aislamiento de la pared y techo del depósito interior.

- Montaje de tuberias, electricidad e instrumentación.

- Purgado del Tanque y tuberías.

- Enfriamiento y pruebas operacionales.

\section{CIMENTACIÓN}

Para dejar libertad de movimientos al muro cilindrico, durante y después de su tesado, se ejecutó la losa de cimentación en dos etapas, una anterior y otra posterior al tesado del muro.
En la primera etapa se construyó la zona central y la exterior de la losa, dejando entre ambas partes un anillo circular sin hormigonar que constituye la segunda etapa (Foto 1).

Se aseguran los posibles movimientos de la zona exterior, no haciendo solidaria ésta con la interior, evitándose armaduras comunes y pasantes y haciendo solapes en la zona anular de la segunda fase. De la misma forma los tubos de calefacción van empalmados en la zona anular mediante manguitos que permiten un pequeño desplazamiento.

La zona central, se hormigonó a su vez dividida en cinco sectores, uno interior y otros cuatro exteriores con juntas radiales.

La zona exterior también se hormigona dividida en cuatro partes con juntas radiales.

Es importante asegurar la estanquidad de los tubos de calefacción antes del hormigonado, para evitar la introducción de lechada de cemento que los obstruya. Por esta causa los manguitos de unión de los tubos son roscados y se deben proteger antes de hormigonar.

En la zona exterior de la losa quedan colocados los anclajes del depósito interior. Para evitar salpicaduras de hormigón se cubren dichos anclajes convenientemente y se mantienen asi hasta el momento de iniciar los trabajos de soldadura en el tanque interior $9 \%$ Niquel.

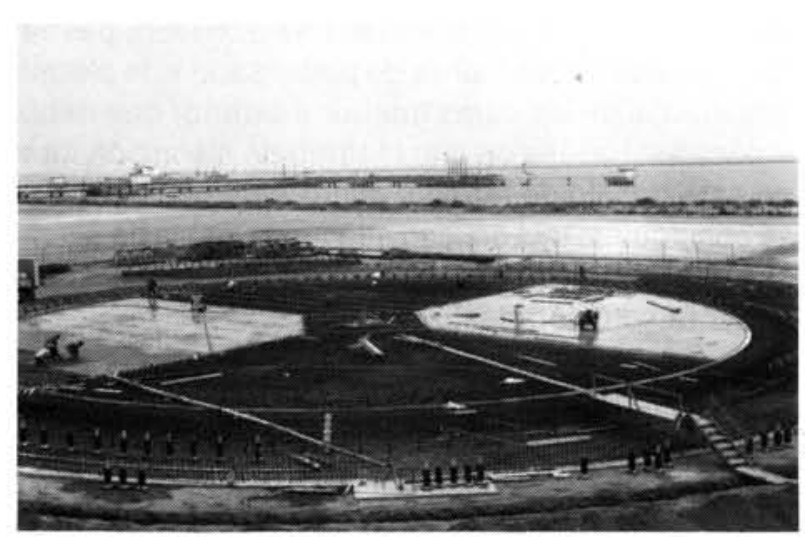

Foto 1 
Desde el punto de vista del control de obra, antes de iniciar el hormigonado se comprueba la granulometria y el contenido de materia orgánica de los áridos acopiados, así como la temperatura y $\mathrm{pH}$ del agua a emplear en la fabricación y curado del hormigón.

Durante el hormigonado se lleva un control horario de producción de hormigón.

Para cada tongada de hormigón se toman doce muestras de hormigón de cinco probetas por toma, midiéndose en el momento de la toma la temperatura ambiente, la temperatura del hormigón fresco y la consistencia.

De las cinco probetas de cada toma, dos se rompen a los 7 dias y otras dos a 28 dias, quedando la quinta. como reserva a emplear cuando se produzcan roturas anormales por fallo de ejecución de probetas.

El acero para armar CRIO-500 de fabricación nacional fue sometido previamente a su utilización en la obra, a ensayos de calificación y rutina consistentes en ensayos de tracción a baja temperatura $\left(-170^{\circ} \mathrm{C}\right)$.

En obra se emite un informe de recepción que sirve para controlar la calidad del acero suministrado y el cumplimiento de las especificaciones contractuales, comprobación de la identificación, de la documentación de origen, del almacenamiento y de los posibles daños por transporte.

Igualmente, para los cables de postesado, con alambre de fabricación también nacional, calidad ASTM A-416 grado 270, se emite en obra un informe de recepción que incluye los certificados de calidad del fabricante, del suministrador y la aceptación del control de calidad del constructor.

\section{DEPÓSITO EXTERIOR}

La solución de deslizamiento del muro cilíndrico se descartó por la cuantia elevada de armadura pasiva y la gran cantidad de vainas de pretensado y de pletinas embebidas en las caras interior y exterior que debian colocarse. La idea de que el ritmo de ejecución de todo este trabajo de ferralla, vainas y pletinas, para que se consiguiera una calidad adecuada, debia de ser mucho menor que el ritmo de hormigonado; llevó a abandonar la solución deslizada.

Este planteamiento, unido a la condición de no realizar juntas verticales en el hormigón, obligó a hacer el muro en tongadas completas, es decir, de todo el perimetro. En resumen, se ejecutó el muro por tongadas completas, con encofrado trepante.



Foto 2

Antes de iniciar el muro se dejan embebidas en la losa de cimentación las vainas verticales de postesado en $\mathrm{J}$ y L, constituidas por tubos metálicos lisos precurvados.

Las placas de acero inoxidable de anclaje del tanque interior a la losa, quedan aisladas del hormigón por un cilindro metálico hueco y provisionalmente durante la construcción por un plástico (Foto 2).

La armadura correspondiente a la primera tongada del muro tiene tres capas: interior, exterior e intermedia. La interior y la intermedia continúan en las tongadas sucesivas hasta la coronación del muro, mientras que la exterior hace la figura del tacón y acaba en esta primera tongada (Foto 3 ).

Mientras un equipo avanza en la colocación de los soportes del liner metálico interior, otro coloca el encofrado interior.

Los soportes vienen cortados de taller a medida de la tongada y previamente a su colocación se les ha soldado en el taller los pernos de anclaje. Quedan sujetos a la ferralla mediante alambre de atar, estando también unidos al encofrado para lograr que queden en la superficie de la cara interior del muro de hormigón (Foto 4$)$.

En la foto se observa la junta anular de la losa y el arranque del muro con las vainas del pretensado vertical embebidas parcialmente en la losa.

Subiendo con el encofrado se va montando una escalera tubular de acceso que se arriostra al muro de hormigón y sirve, tanto de acceso al personal, como para la subida de mangueras de agua, aire y conducciones eléctricas.

La colocación de hormigón se hace con dos medios: bomba sobre camión y pluma de distribución, montada sobre una torre de grúa desplazable sobre una vía circular que rodea el tanque. 


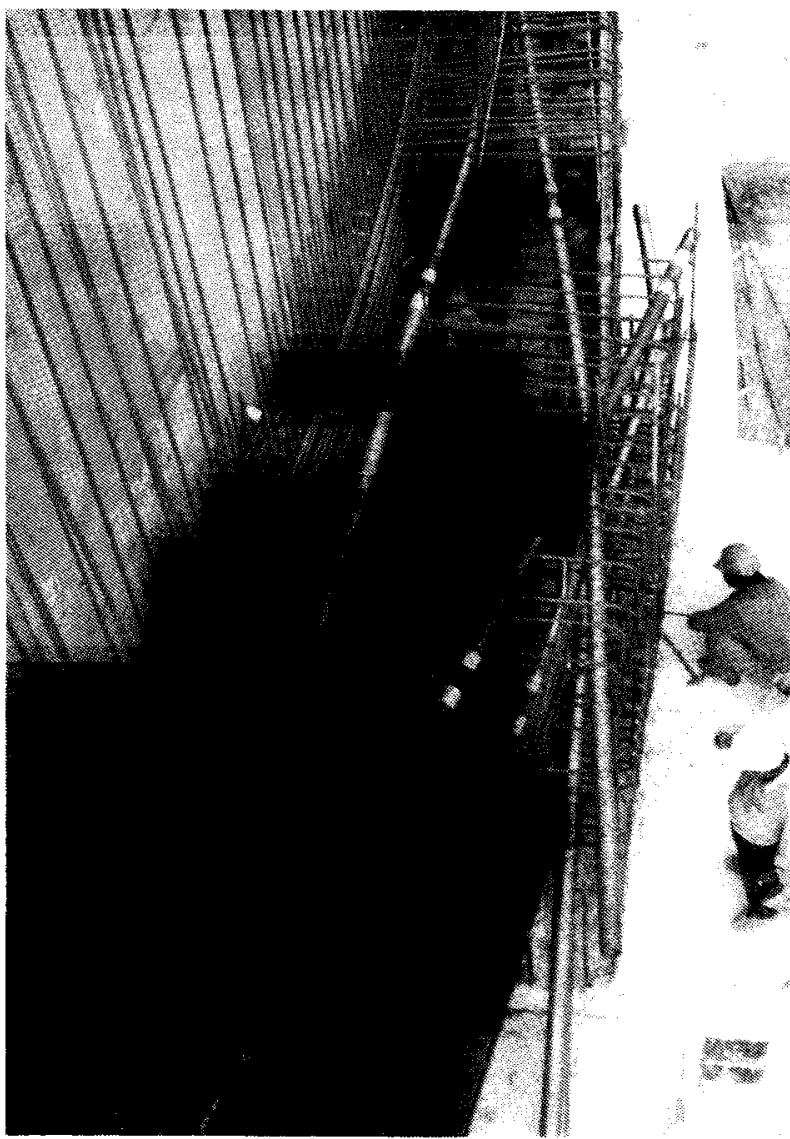

Foto 3

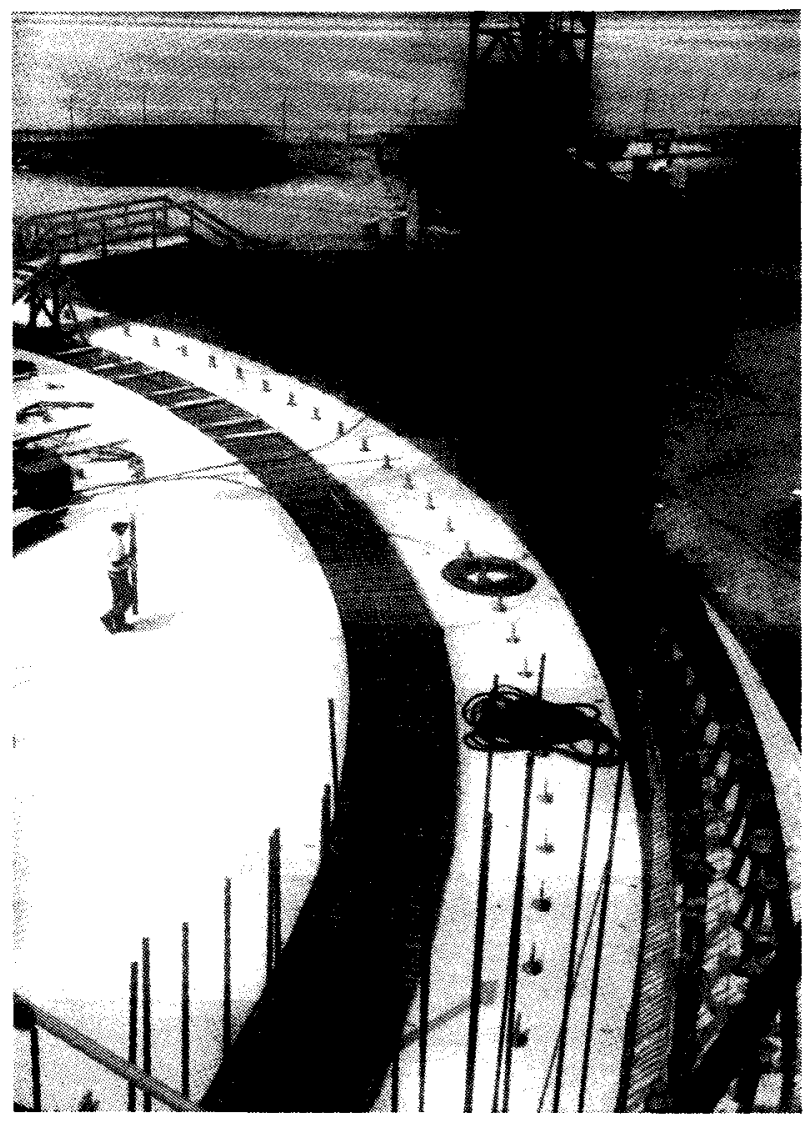

Foto 5

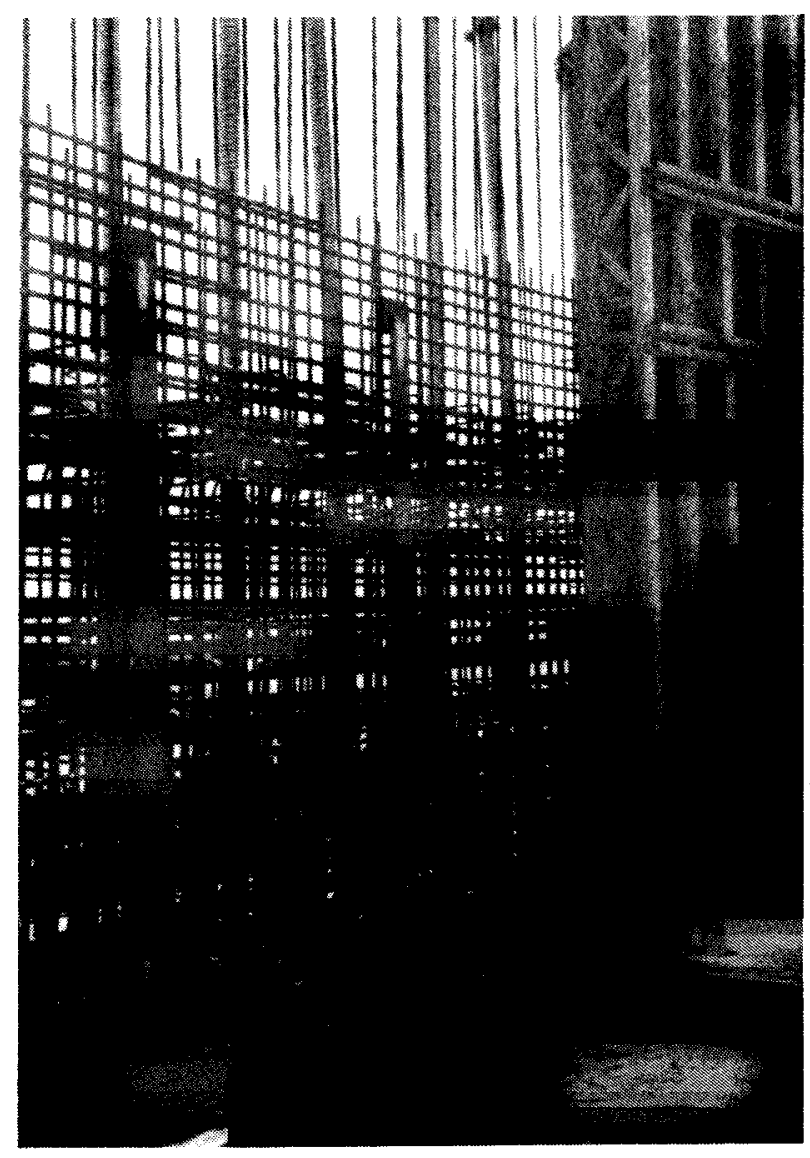

Foto 4

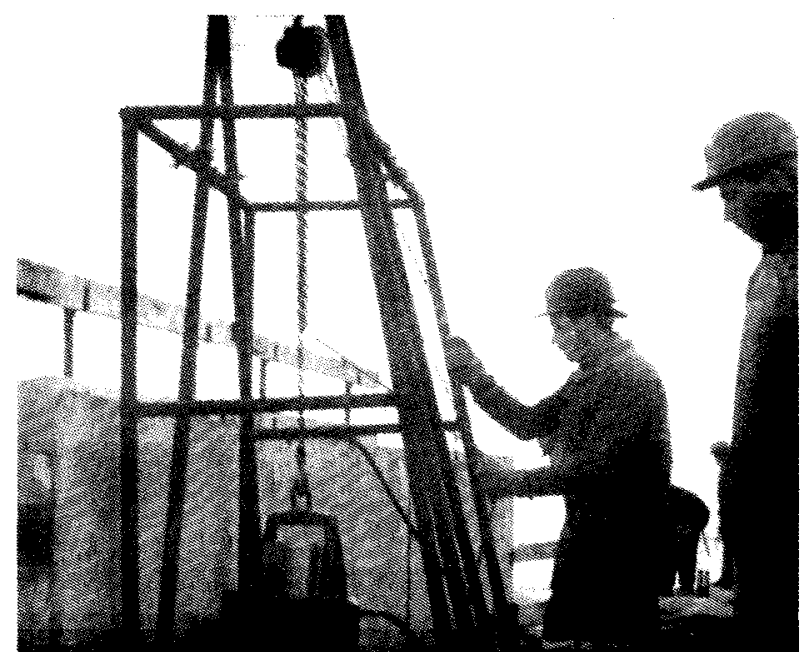

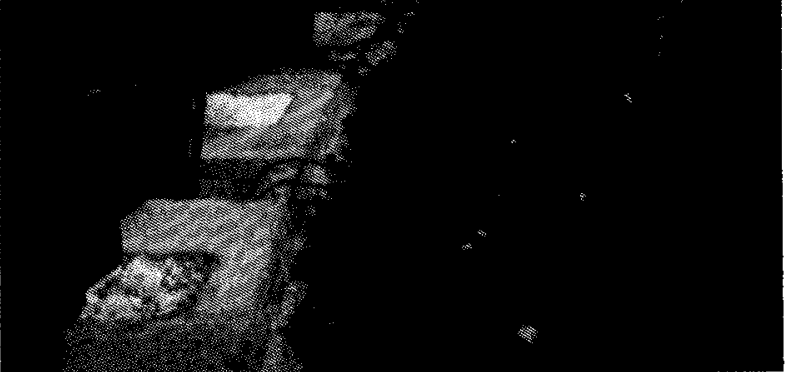

Foto 6

http://informesdelaconstruccion.revistas.csic.es 
Para evitar la formación de juntas frías se empieza el hormigonado con los dos medios de colocación hormigonando en una misma zona hasta alcanzar el llenado completo en altura de la tongada, separándose paulatinamente el camión bomba hacia un lado y la pluma hacia el otro.

La armadura pasiva consiste en dos parrillas de acero CRIO-500, unidas por estribos con densidad disminuyendo con la altura del muro.

En el tacón y en los metros inferiores del muro la armadura horizontal interior está reforzada con mayor número de barras de mayor diámetro.

En el postesado vertical las bobinas a enfilar se suben con una grúa a la coronación del muro cilíndrico, donde se colocan en una debobinadora de tripode.

Con la enfiladora colocada sobre la coronación del muro se enfilan los tendones cable a cable, sujetándose con cuñas en las cabezas del anclaje.

El tesado se hace con todos los alambres al mismo tiempo, desde la parte superior del muro, efectuándose el retesado posterior por el extremo inferior. Se llega a una tensión de tesado del $80 \%$ de rotura y se ancla al $70 \%$ de rotura (Foto 6 ).

Previamente a la inyección se hormigonan los cajetines de tesado. Se comprueba la inyectabilidad del tendón introduciéndole aire a presión por una purga y comprobando que sale por la opuesta. La lechada de inyección está compuesta por agua, cemento y un aditivo.

Para el postesado horizontal las bobinas se colocan en el suelo junto a cada contrafuerte, en debobinadora de trípode. El enfilado, tesado e inyección son idénticos a los de postesado vertical, con la única diferencia de la necesidad de cestas colgadas como andamios de trabajo.

Tanto los tendones horizontales como verticales van alojados en unas vainas metálicas flexibles rectas que se adaptan en obra al radio que pide el trazado correspondiente de cada tendón. Solamente en las curvas de pequeño radio correspondientes a los tendones verticales en J, las vainas están materializadas por tubos rígidos lisos precurvados en taller.

El control de ob́ra se efectuó de forma similar al lleva. do para la losa, con la particularidad de que en el hormigonado, en cada tongada se dejan embebidos dos termopares que servirán para conocer la curva de temperatura del hormigón desde el momento del vertido, durante el fraguado y endurecimiento del mismo, y posteriormente hasta 48 o 72 horas.
Se alcanzaron temperaturas de $60-70^{\circ} \mathrm{C}$ máximas a las 15-20 horas del vertido, disminuyendo posteriormente.

El tiempo normal de ejecución de cada tongada osciló de una a dos semanas, según los movimientos de encofrados necesarios.

\section{CÚPULA}

El montaje de la cúpula metálica de acero carbono y del techo suspendido de aluminio se hace en el fondo del tanque (Foto n. ${ }^{\circ}$ ). La cúpula está formada por chapas radiales mpntadas sobre perfiles alineados circularmente. Tanto éstos como las chapas han sido prefabricados anteriormente en taller. Una vez terminado su montaje, simultaneado con el del muro exterior de hormigón, se procede a elevar el conjunto cúpula-techo suspendido mediante aire, que se introduce en su espacio inferior por medio de una serie de ventiladores colocados provisionalmente sobre las tubuladuras que, para una función definitiva, se han dejado en la cúpula (Foto 8).

El hormigonado se hace posteriormente en varias etapas, la primera de las cuales es el anillo de borde que incluye los anclajes de los tendones verticales, soportados por camillas metálicas circulares sobre las que éstos se replantean cuidadosamente. Se utiliza como enconfrado exterior uno idéntico al del muro, y por el interior se hace una junta con nervometal.

El hormigonado se realiza también con las dos bombas antes citadas, una de ellas conectada a la pluma de distribución que rueda sobre carriles al rededor del tanque y la otra a una tubería fija que sube por la pared vertical cilíndrica y luego se prolonga hasta el lugar del vertido. Este equipo es secundario, sirviendo para reforzar uno de los frentes de hormigonado evitándose la formación de juntas "frías" de hormigonado.

La siguiente etapa es la cúpula propiamente dicha dividida a su vez en tres tongadas sucesivas de hormigonado.

Al hormigonarse directamente sobre la cúpula metálica y para evitar deformaciones se somete a ésta a presión interior mediante la introducción de aire por debajo, en proceso análogo al izado de la cúpula. Esta situación se mantiene desde el inicio de la primera tongada hasta tres días después de terminada la tercera, una vez comprobada la resistencia del hormigón mediante la rotura en laboratorio de las probetas preparadas al efecto.

La ejecución de hormigón se realiza también con dos equipos de forma análoga al anillo de borde (Foto 9). Las juntas entre tongadas se hacen con nervometal perpendicularmente a la cúpula metálica. 


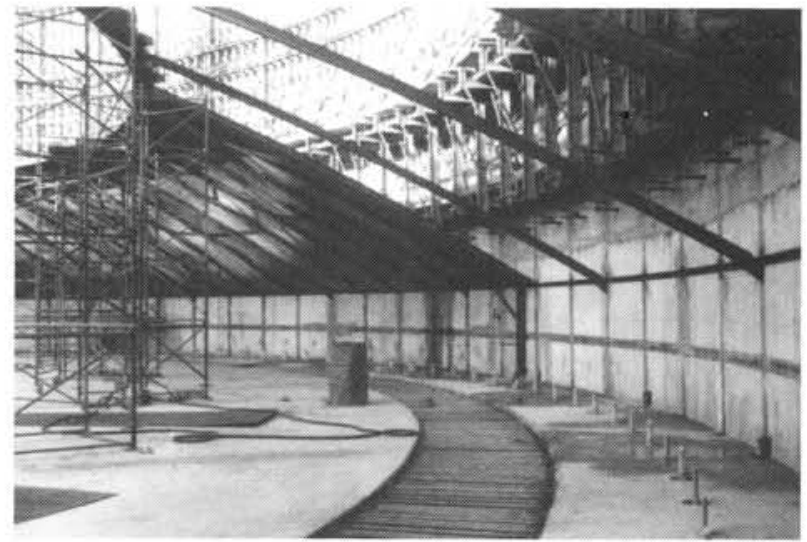

Foto 7

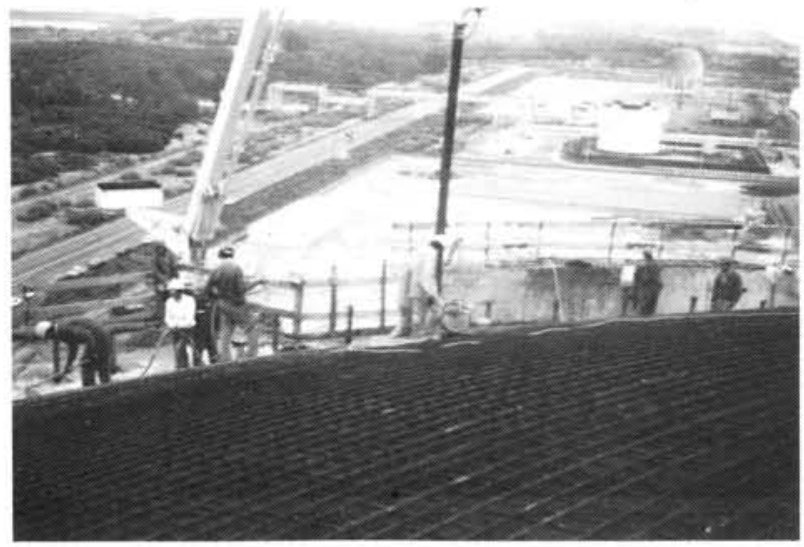

Foto 9

Antes de hormigonar la siguiente tongada, y aprovechando la noche, se sanea la junta de tal manera que en tres dias sucesivos se pueda terminar el hormigonado total de la cúpula.

Las características y control de obra de los materiales de la cúpula son análogos a los de la losa de cimentación.

\section{DEPÓSITO INTERIOR}

La pared vertical del depósito interior está constituida por una serie de virolas formadas por soldadura de chapas de acero $9 \%$ Níquel. Este tipo de acero no se fabrica en España, y ha sido necesaria su importación. Las chapas se prefabrican y curvan en taller, llegando en estas condiciones a la obra, almacenándose en el exterior del tanque.

Se introducen en el interior, según van siendo necesarias, a través de la puerta provisional dejada al efecto en el muro exterior y mediante el uso de unos carros que ruedan sobre perfiles dispuestos en la plataforma de acceso. Una vez en el interior, se colocan en posición, con el auxilio de otros carros motorizados que circulan por un monocarril fijado a la cúpula (Foto 10). Finalmente se sueldan unas a otras, utilizando una máquina automática para las soldaduras horizontales y de forma manual las verticales.

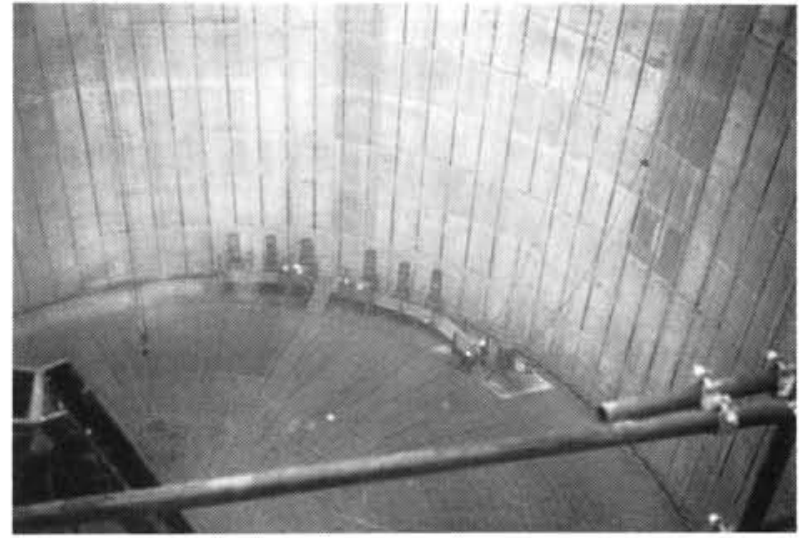

Foto 8

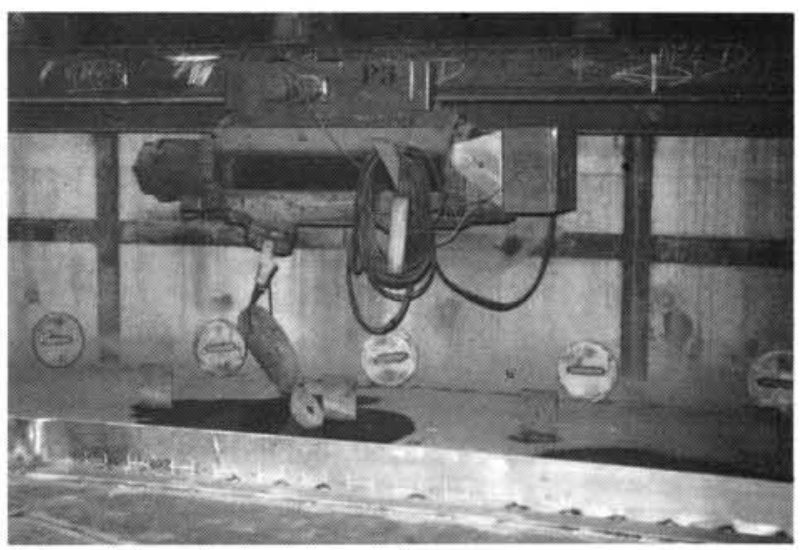

Foto 10

Previamente a la primera virola de la pared vertical se ha montado el anillo de borde del fondo, que apoya sobre una viga anular de hormigón ligero y de baja conductividad, que constituye la cimentación del depósito interior (Foto 11).

El resto del fondo del depósito interior se monta y suelda posteriormente. Está constituido por chapas también de acero $9 \%$ Niquel, preparadas en taller antes de su llegada a obra. Su entrada al interior se hace de igual forma que las de la pared vertical.

\section{INSTALACIONES}

Las tuberias interiores se prefabrican, montan y sueldan in situ, sobre el suelo a longitud total. Posteriormente, se colocan en posición mediante una grúa de $130 \mathrm{~m}$ de pluma y $300 \mathrm{t}$ de capacidad (Fotos 12 y 13).

Las tuberias exteriores se prefabrican, montan y sueldan parcialmente in situ, sobre el suelo (Foto 14). Posteriormente se colocan en posición, por tramos, realizando las soldaduras de unión (Foto 15).

Todo el cableado eléctrico para alumbrado, fuerza e instrumentación, se efectúa a través de bandejas metálicas situadas en las escaleras, plataforma de servicio del tanque, tacón de la losa y barandilla perimetral de la cúpula. 


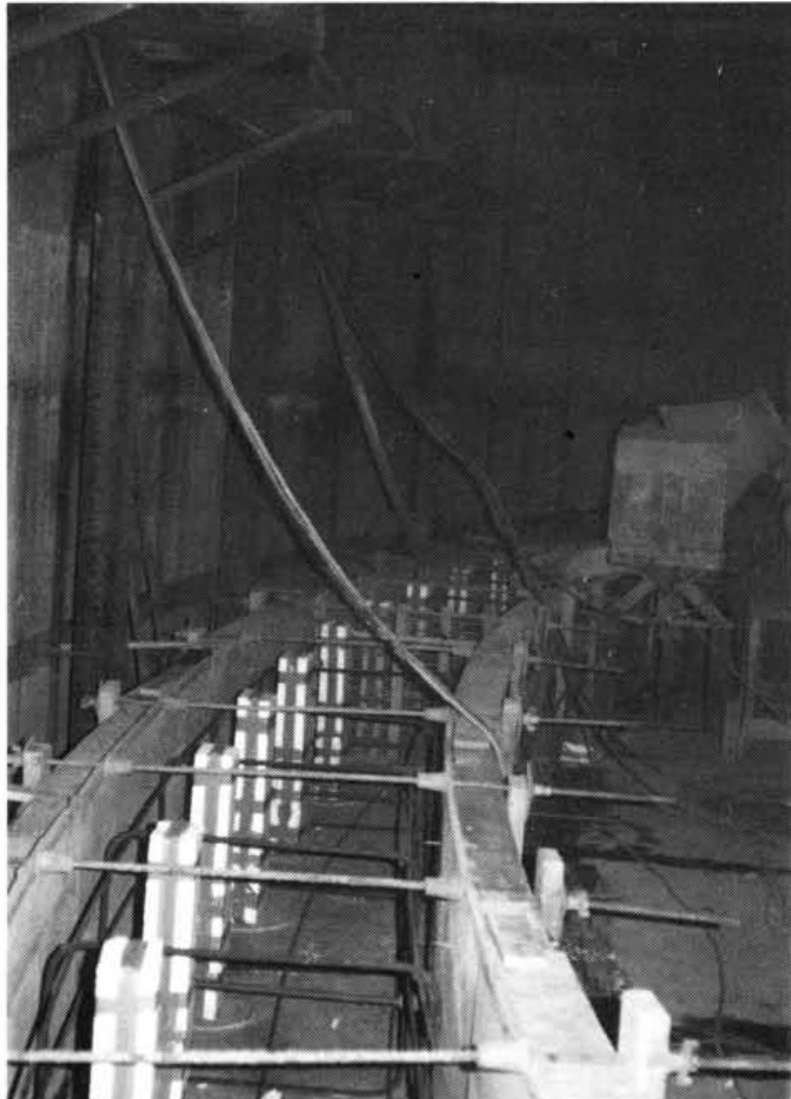

Foto 11

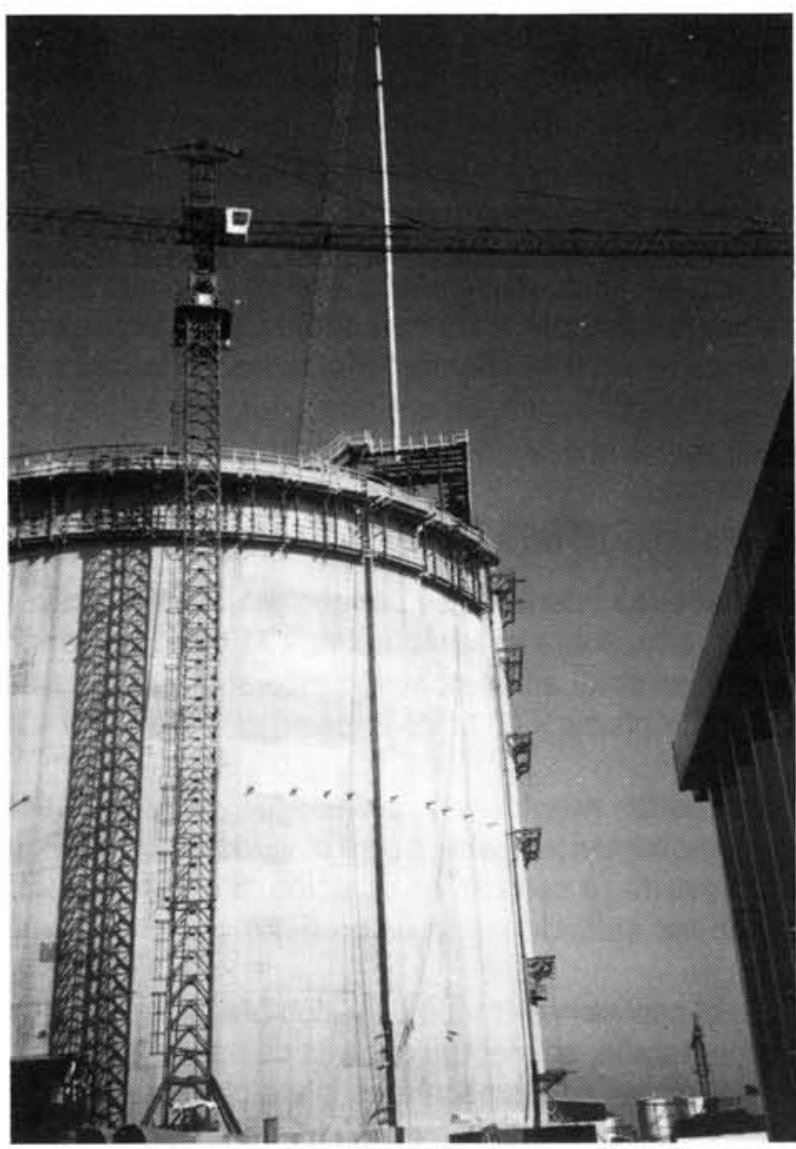

Foto 13

(c) Consejo Superior de Investigaciones Científicas Licencia Creative Commons 3.0 España (by-nc)

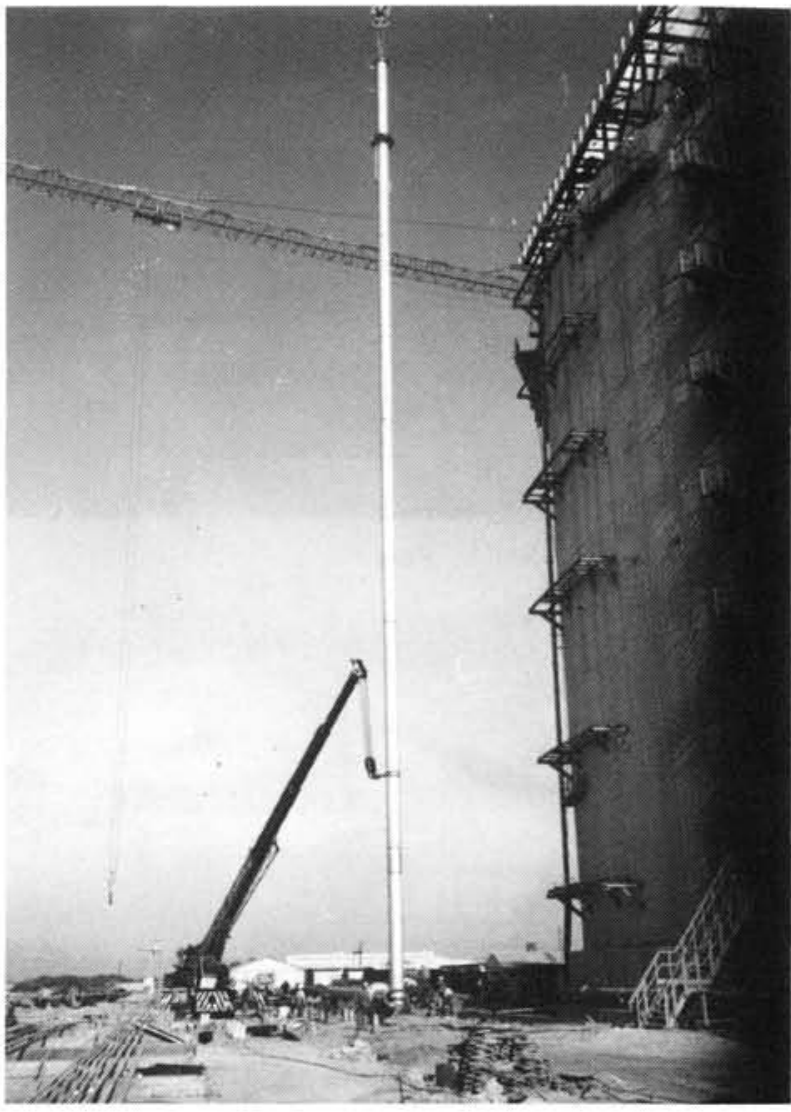

Foto 12

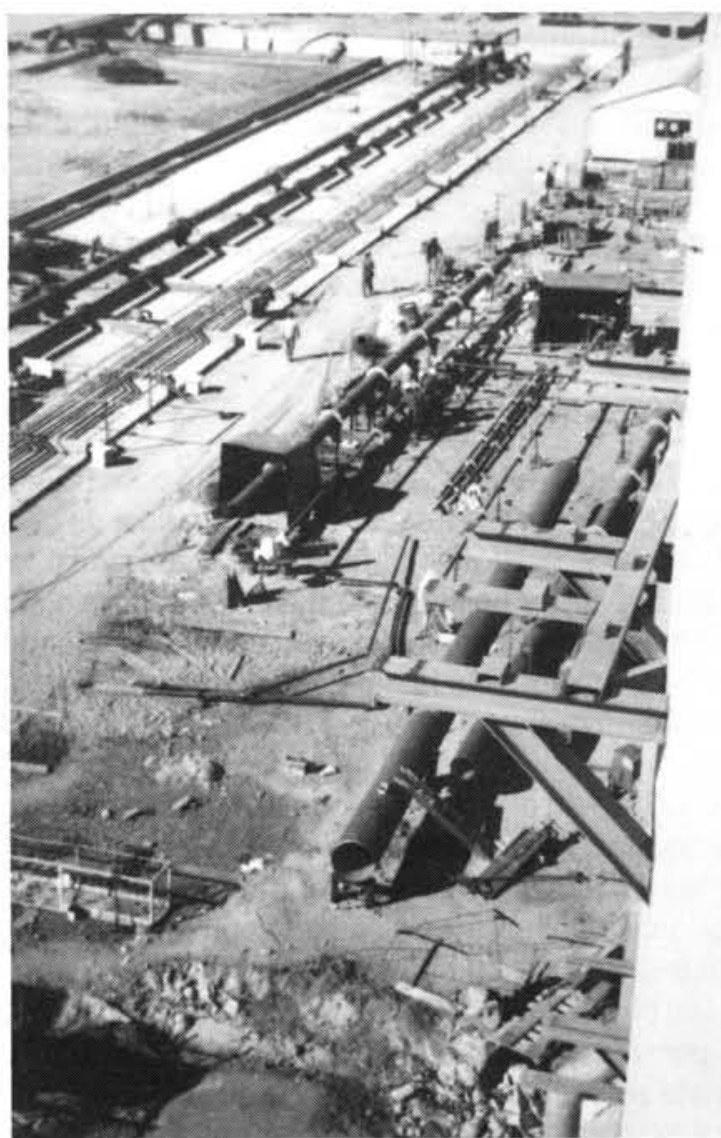

Foto 14

http://informesdelaconstruccion.revistas.csic.es 
La instrumentación necesaria para el mantenimiento y operación del tanque se coloca en bastidores metálicos situados en la plataforma de servicio de la cúpula (Foto 16).

\section{AISLAMIENTO}

El aislamiento de fondo está formado por bloques de "Foam-Glass" unidos mediante una mástique de betún asfáltico en caliente. Se colocan varias capas hasta alcanzar un espesor de $700 \mathrm{~mm}$.

La pared del tanque interior se aisla mediante una manta elástica de fibra de vidrio que se introduce a través de la puerta de acceso, arrastrada por unos rodillos para ser fijada finalmente a las virolas metálicas.

La cámara intermedia entre las paredes de los dos tanques se rellena con perlita expandida y vibrada, introduciéndose en el tanque a través de las tubuladuras especificas de la cúpula. También a través de éllas se introducen los vibradores especiales con los que se realiza el vibrado.

La perlita expandida se fabricó in situ, mediante un horno especial, a partir del material mineral original, también de importación, al no producirse en España mineral de las características adecuadas (Foto 17).

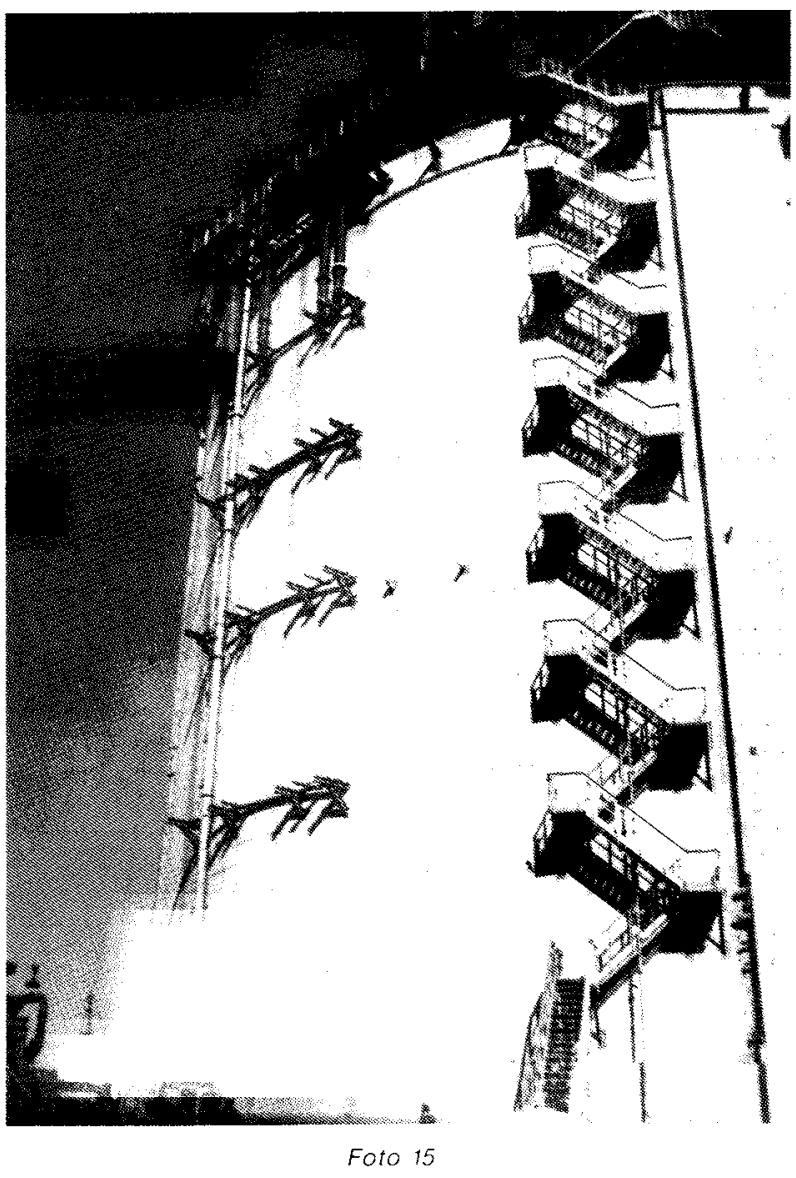

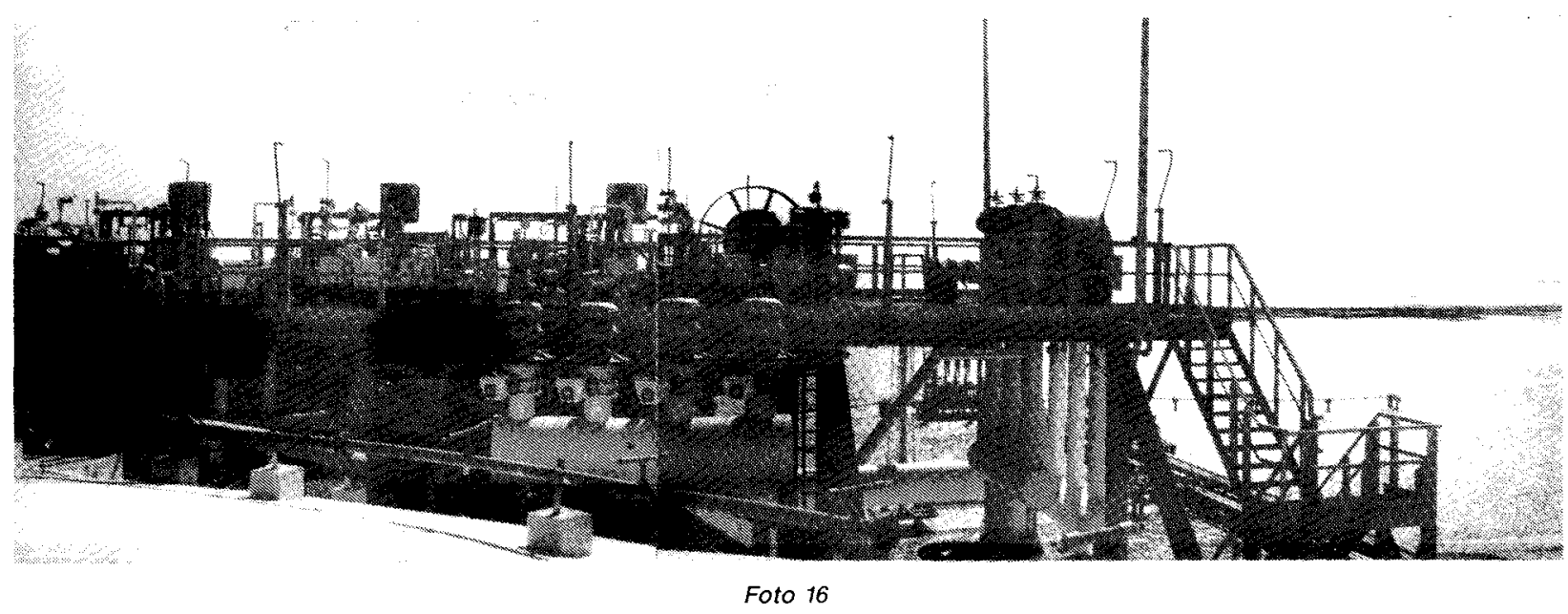

El techo del tanque interior se aisla mediante fibra de vidrio, colocada en capas y. atada al techo.

Del mismo modo se aislaron todas las penetraciones en la cúpula.

\section{PRUEBAS}

Todos los componentes del tanque, comenzando por el depósito interior, fueron probados antes ylo después del montaje.

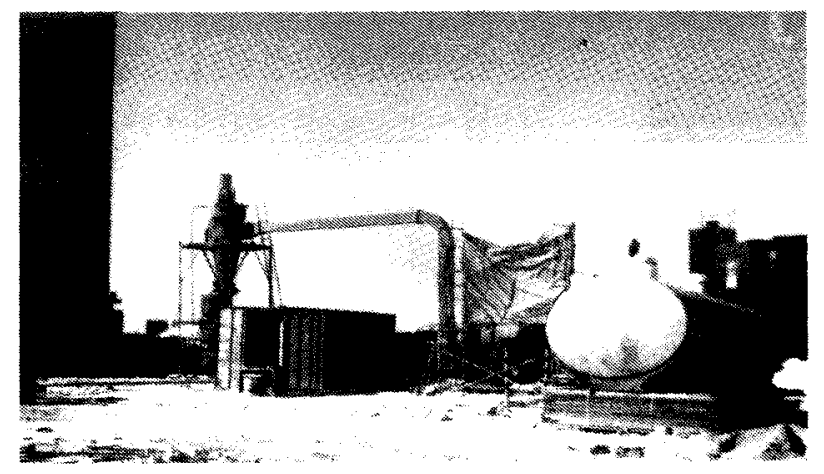

Foto 17 


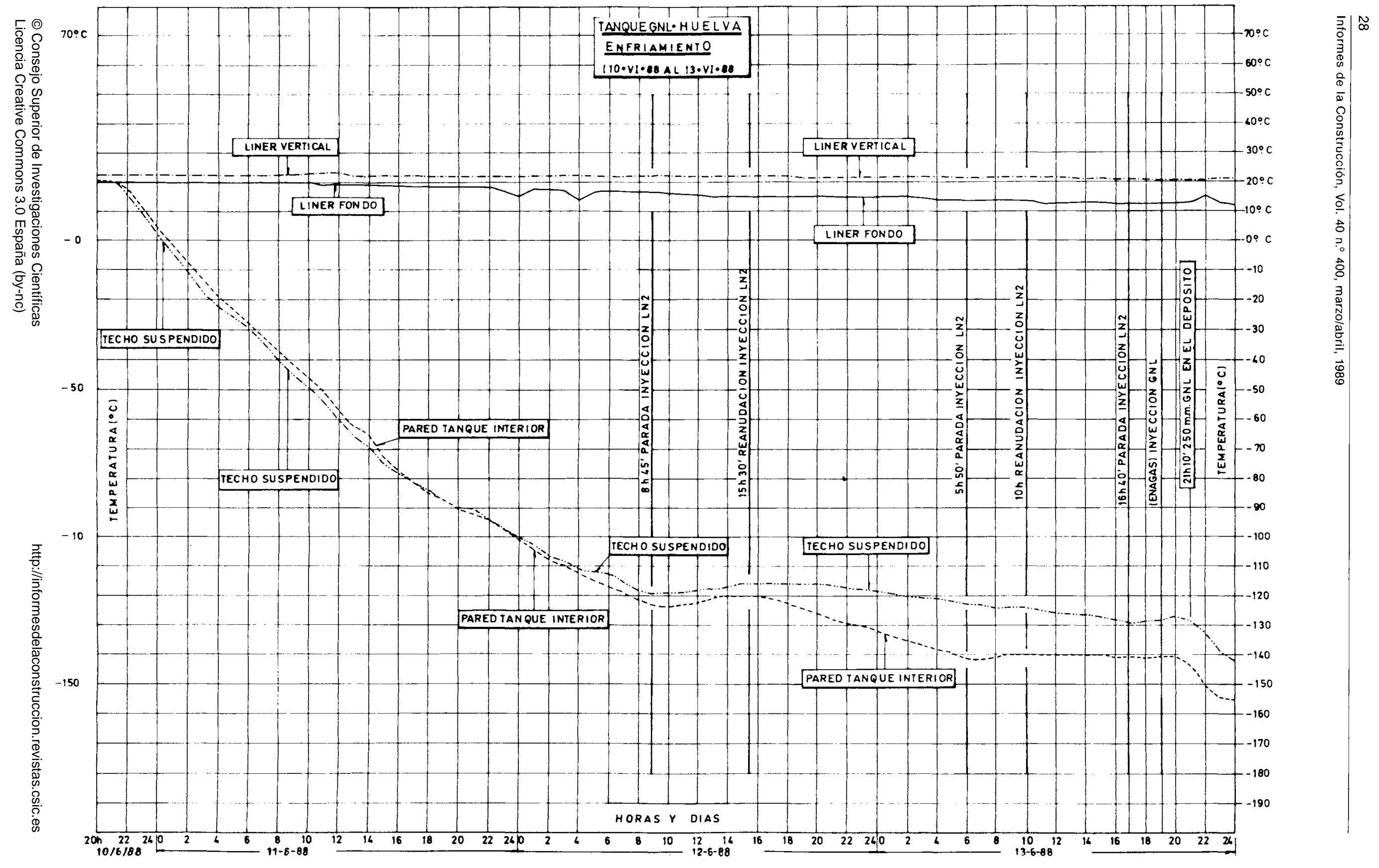




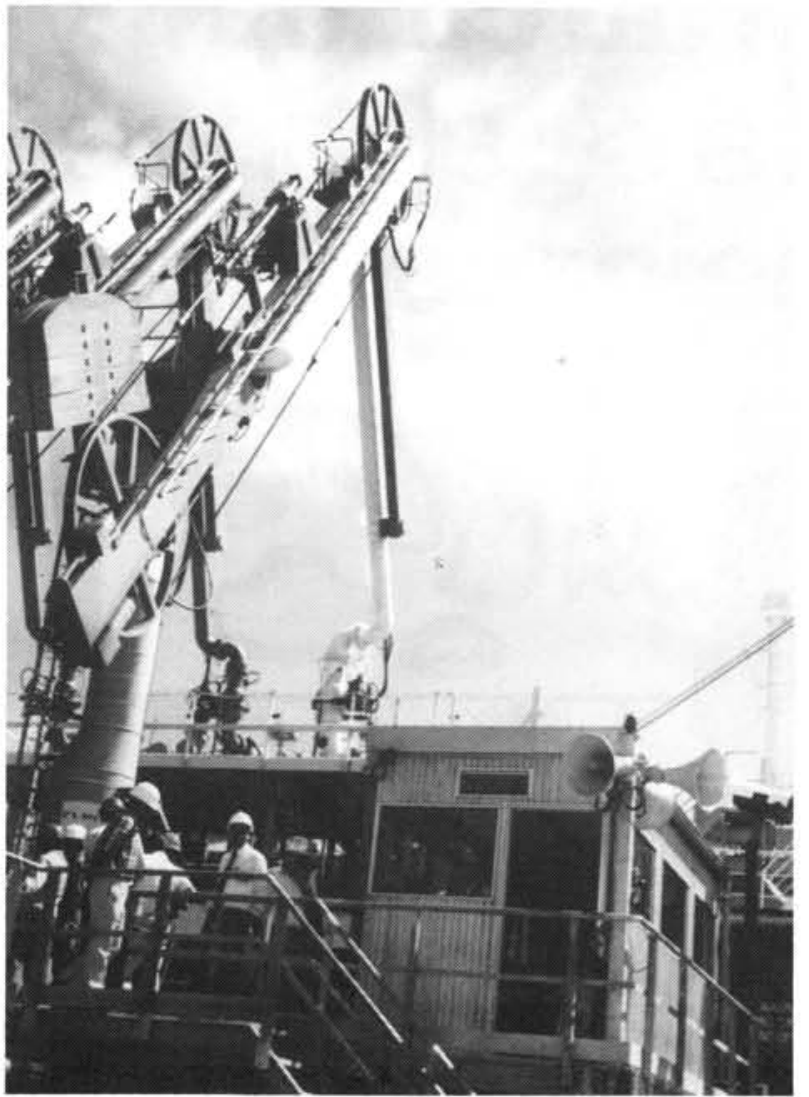

Foto 18
El depósito interior se llenó de agua hasta una altura de $36.465 \mathrm{~mm}$ para comprobar su estanquidad y la debida capacidad portante, tanto de su apoyo directo como de la losa de cimentación y suelo.

Posteriormente, el depósito fue sometido a una presión de $362 \mathrm{mb}$ y a un vacio de $10 \mathrm{mb}$, para comprobar la estanquidad del conjunto "liner-depósito" exterior.

Todas las tuberias del tanque, interiores o exteriores, fueron ensayadas a diferentes presiones, neumática o hidráulicamente, según el valor del diseño.

Se comprobó el correcto funcionamiento de todas las válvulas, circuitos eléctricos y neumáticos en taller e in situ, asi como la correspondiente instrumentación y equipos.

El purgado se realizó introduciendo nitrógeno-gas para secado del tanque en su conjunto, midiéndose una serie de parámetros: punto de rocío, contenido de oxigeno, temperatura y presión, hasta conseguir los valo. res deseados.

La prueba definitiva del tanque es naturalmente el enfriamiento del mismo, para lo cual se introdujo paulatinamente nitrógeno líquido hasta conseguir una estabilización de la temperatura interna, siguiendo a continuación el llenado definitivo con GNL, procedente del primer metanero que atracó en el terminal (Foto 18). Puede observarse la curva de enfriamiento en la gráfica de la página anterior.

\title{
publicación del IETcc / CSIC
}

\begin{abstract}
La experiencia nacional en construcción industrializada en la última década, aunque no abundante, puede resultar paralizante. Como reacción, este trabajo trata de elaborar y ordenar la información que. pegado al terreno, se ha acumulado durante los sesenta.

Auscultando tendencias avanzadas en otros paises y apoyándose en nuestra realidad cotidiana, el autor de este trabajo apuesta por la industrialización, presintiendo un futuro con pocos puntos en común con lo que en general, hasta bien reciente, se ha conocido como construcción industrializada.

Se abre el trabajo con un prólogo del Profesor Ciribini en el cual, con rigor conceptual y desde su rica experiencia, analiza algunos de los conceptos más polémicos del fenómeno de industrialización del sector construcción. El autor recopila un conjunto de aportaciones de maestros de la arquitectura al lento proceso de evolución tecnológica y conceptual, continuando con un intento de respuesta realista a la interrogante que flota en el sector nacional: ¿réquiem por la industrialización?

Se dedican otros capitulos a revisar lo realizado y a encarar el futuro inmediato: el concepto de componente, su repercusión económica, la dificultad del proyecto a base de productos industriales, la nueva vigencia embrionaria de la construcción por medio de catálogos, los conceptos de flexibilidad e intercambiabilidad desde una óptica práctica... Especial atención dedica este trabajo a la exposición de lo que podiamos llamar nuevos derroteros de la coordinación dimensional, aportando una visión actualizada
\end{abstract}

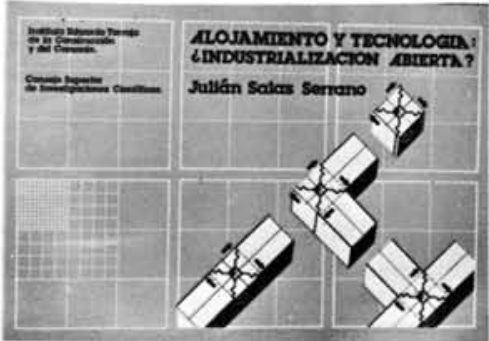
y pragmática de los enfoques más implantados en Europa.

Las siempre problemáticas interrelaciones entre normativa, calidad e industria se detallan de forma documentada y realista. Finaliza el trabajo con unas reflexiones dirigidas al ámbito empresarial y un esbozo de sreglas de juegon que faciliten al subsector la salida del kimpasse» actual.

Un volumen encuadernado en rủstica, de $24 \times 16,5 \mathrm{~cm}$, compuesto de 160 páginas, con 109 figuras, 19 tablas y 86 referencias bibliográficas. Madrid, junio, 1981 . 